\title{
Erratum to: Neonicotinoid insecticides translocated in guttated droplets of seed-treated maize and wheat: a threat to honey bees?
}

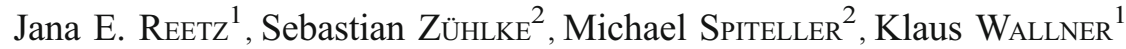 \\ ${ }^{1}$ Apicultural State Institute, University of Hohenheim, August-von-Hartmann-Str. 13, 70593, Stuttgart, Germany \\ ${ }^{2}$ Institute of Environmental Research (INFU), Technische Universität Dortmund, Otto-Hahn-Str. 6, 44227, \\ Dortmund, Germany
}

Erratum to: Apidologie

DOI 10.1007/s13592-011-0049-1

\section{MATERIALS AND METHODS}

\subsection{Plant material}

\subsubsection{Triticale experiments}

The submitted specifications of the insecticide Gasur and the fungicide Efa of the treated seed in triticale have to be reduced by the factor 100 (which corresponds to the recommended application rate):

Seeds of triticale were treated with a combination of the insecticide Gasur $^{\circledR}$ (per seed: $0.0175 \mathrm{mg}$ imidacloprid, Bayer CropScience AG, Leverkusen, Germany) and the fungicide $\mathrm{Efa}^{\circledR}$ (per seed: $0.0006 \mathrm{mg}$ triazoxide, $0.000225 \mathrm{mg}$ tebuconazole, $0.00225 \mathrm{mg}$ fluoxastrobin, $0.0015 \mathrm{mg}$ prothioconazole; Bayer CropScience AG, Leverkusen, Germany).

This error has no influence on results and discussion, respectively, because the results (i.e. concentration of pesticides in guttation drops) are not correlated with the application rate.

The online version of the original article can be found at http://dx.doi.org/10.1007/s13592-011-0049-1 . 